\title{
Research of 'Employment-oriented' Talent Cultivation Mode of Tourism Major in the Third Batch Colleges
}

\author{
Yuanyuan Xiu \\ College of Science and Technology, Nanchang \\ University, Nanchang Jiangxi 330029
}

\author{
Weihua Huang \\ College of Science and Technology, Nanchang \\ University, Nanchang Jiangxi 330029
}

\begin{abstract}
Third batch colleges are the products of the popularity and the rapid development of higher education. Through taking advantage of the premium and sufficient educational resources of parent higher universities and combining the advantage of privately-funded colleges to absorb social capital, they have become a new educational form. The production and development of third batch colleges has solved the contradiction of higher education that demand exceeds supply. They have become an indispensable part of higher education and exert irreplaceable function. This paper collects the related data of the national undergraduate institutes and third batch colleges from 2008 to 2014 and analyzes the problems of third batch colleges in the talent cultivation mode. On the basis of this, it studies the talent cultivation mode of third batch colleges through taking the example of tourism major of third batch colleges, proposes the train of thought concerning the 'employment-oriented' talent cultivation mode and also puts forward its development prospect.
\end{abstract}

Key words- third batch colleges; tourism major; employment orientation; cultivation mode

\section{INTRODUCTION}

To cultivate the high-quality talents is the target of all the activities of tourism major in third batch colleges and is the life line of tourism major. In the current days when the competition of higher education is extremely heated, the key for the tourism major in third batch colleges to gain development in competition is to cultivate high-quality special talents that adapt to the social demands.

\section{Proposing of the Problem}

Since 2003 when Ministry of Education proposed the concept of third batch colleges, they have developed in recruitment scale and graduate number for 12 years. Take the data in 2008 as the example; third batch colleges take up $30 \%$ of undergraduate colleges, having greatly boosted the popularity of higher education. The paper collects the number of undergraduate and third batch colleges from 2008 to $2014,{ }^{[1]}$ as is shown in the following chart 1: 
chart 1

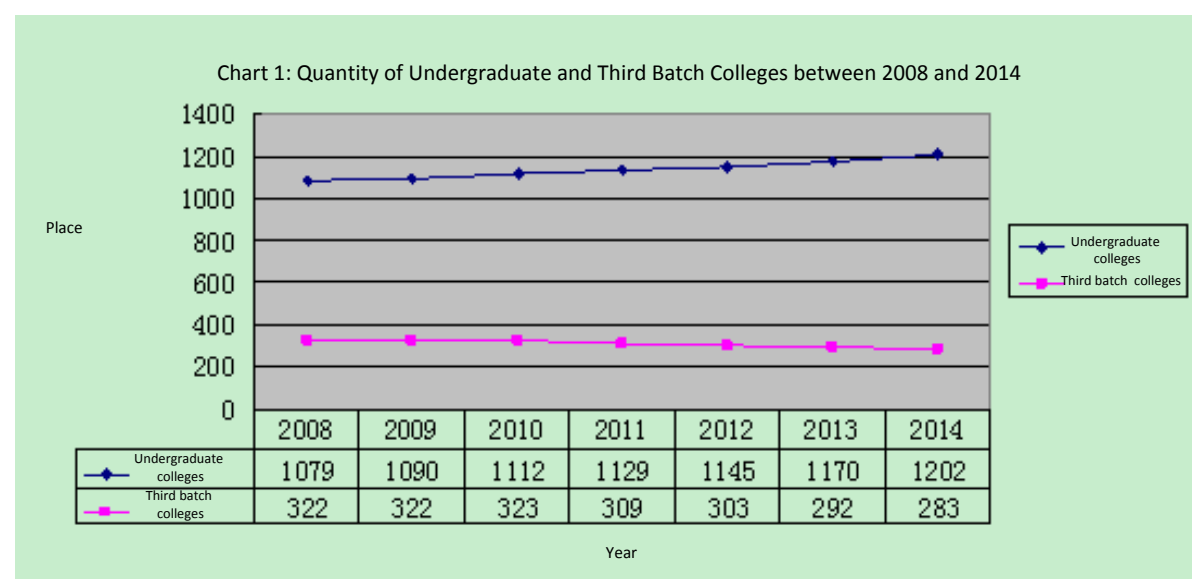

From the above chart, it is shown that the number of undergraduate colleges keeps increasing from 2008 to 2014, while that of the third batch colleges keeps reducing, whose proportion of the undergraduate colleges reduces from $30 \%$ in 2008 to $23 \%$ in 2014 . The increase or decrease of the number of third batch colleges is determined by the society's recognition to some extent, which is directly influenced by the graduate quality and the talent cultivation mode of the third batch colleges. The realistic problem is how to well combine the two. Hence, this paper proposes 'employment-oriented' talent cultivation mode and discuss the talent quality of tourism major in third batch colleges through taking the example of tourism major. It hopes to provide some help and suggestions to other majors and the self-development of third batch colleges through the 'employment-oriented' talent cultivation mode.

\section{Analysis of Talent Cultivation Mode and Students' Employment of Tourism Major in Third Batch Colleges}

(1) Third batch college is a new-born thing; in order to better adapt to the society's new requirements of talents, the talent cultivation mode of tourism majors in the third batch colleges should an operating mode to cultivate the senior application-oriented technical talents with innovative spirits and ability through targeting at the market and the realistic demands according to the development discipline of higher education and the objective reality. In terms of talent cultivation, tourism major of third batch colleges should emphasize to cultivate the application-oriented technical talents, which means that the talents should have both strong learning ability and practice ability rather than be the research-oriented, academic or technical talents; in terms of construction of students' knowledge system, tourism major should focus on the application ability to formulate the according cultivation scheme and construct students' application-oriented knowledge system rather than focus on the disciplines; in terms of curriculum system, that of tourism major should highlight the applicability, flexibility, pertinence and modularity rather than only pursue the systematicness and completeness of the curriculum system; tourism major should attach importance to the cultivation of practice ability of students. Proportion of practice and theory teaching should be coordinated; theory teaching can be put in the practice teaching, thus enabling students to learn through practice and then master and apply the knowledge. In addition, tourism major in third batch colleges can adopt the teaching mode of research and learning and depend on the industries to openly run the school rather than closely run the school. Talent cultivation mode of tourism major in 
third batch colleges should be special and innovative; only in this way can they cultivate the high-quality talents that accord with the market demands. ${ }^{[2]}$

(2) The Current Employment Situation of Tourism Major in Third Batch Colleges

The development of the society makes tourism become one of the industries with the strongest development momentum and the largest scale in the global economy. The tourism in our country is at the golden development period. As tourism and the related industries keep development and the number of people who travel at home and abroad keeps increasing, various industrial problems also arise. Most of the employees in the tourism industry have low quality and professionalized degree; the entire level of talents has a big gap with the development demands of tourism. In face of the huge demands of the industry, employment of tourism majors in the third batch colleges is very embarrassing. ${ }^{[4]}$ In terms of employment, it is characteristic of low employment rate and high dismission rate. However, in face of the employment competition, they can hardly show their core employment competitiveness. The students seem to only fit for the tourism industry; they lack the ability of substituting students in other majors. Hence it is difficult for other industries to accept them. Meanwhile, in the competition of the enterprises and public institutions related to tourism, the graduates of other majors can replace the graduates of tourism management majors under most conditions. The reality is that most of the managers of tourism enterprises and administrative departments in our country are from other majors. Graduates of tourism majors in third batch colleges lack the employment competitiveness and advantages; the features of their major are not embodied in the reality. ${ }^{[5]}$

\section{Deviation of Talent Cultivation Mode and Students' Employment in Tourism Major of Third Batch Colleges}

1. Investigation and Research Design of Employment Demands of Tourism Majors

In order to deeply study the deviation of the higher education mode of tourism majors and employment demands of students, this paper has conducted questionnaire and investigation of the employment demands of students. The questionnaire studies the related information of five aspects: major cognition, cultivation target, curriculum provision, teaching form and teaching staff; the research objects are the students in junior and senior year in the third batch colleges, including College of Business of Jiangxi Agricultural University, College of Science and Technology of Nanchang University, Jiangxi University of Technology, College of Modern Economic Management, Jiangxi University of Finance and Economics. 300 questionnaires have been handed out and 285 valid questionnaires have been recovered.

2. Deviation between Higher Education Mode of Tourism Major and Employment Demands of Students

From the above chart, it is seen that students' recognition degrees of major cognition, cultivation target, curriculum provision, teaching form and teaching staff are lower than 3 scores, showing that the resources and contents provided for students under the current teaching mode do not meet students' demands for teaching under the current environment. 
Chart 2 Average Value of Students' Satisfaction in the Five Aspects

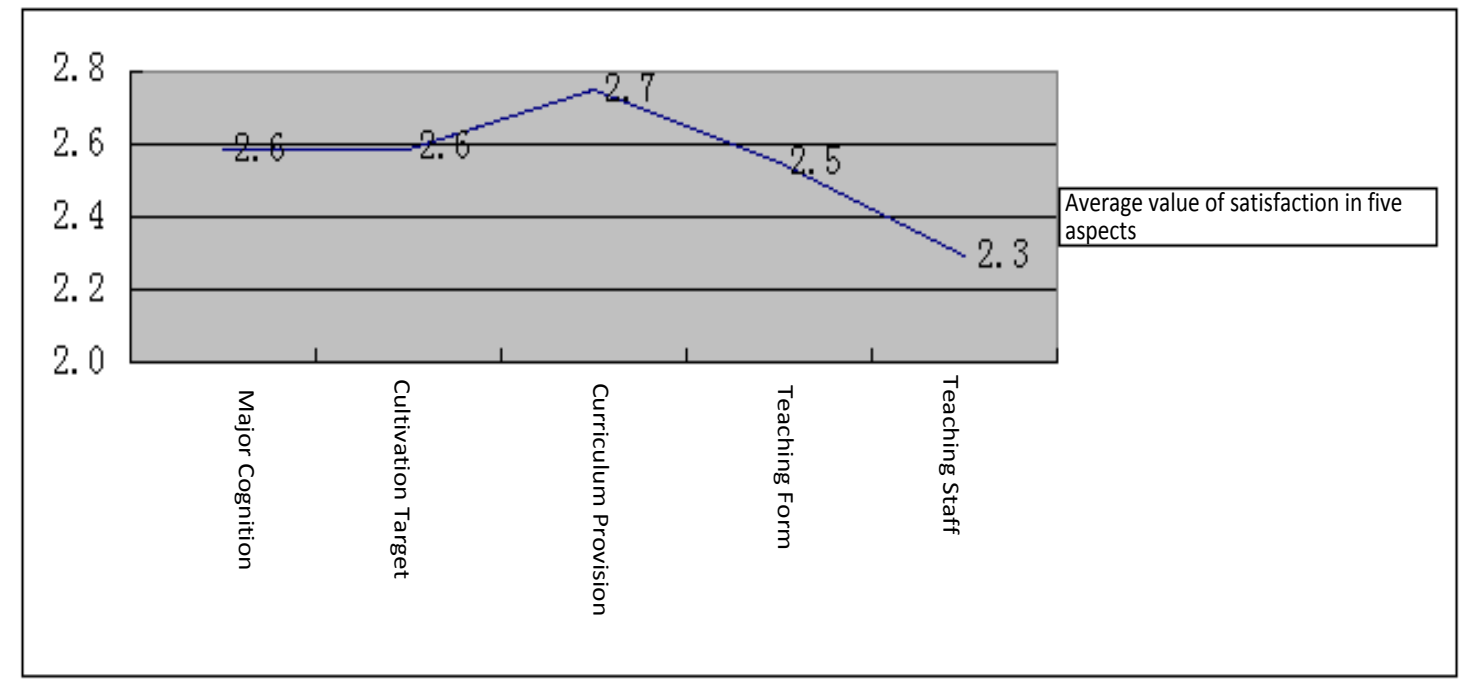

(1) In terms of major cognition, that students know little about the major before choosing the major $(19.6 \%$ know about the major) is the important reason to cause the deviation between the major cognition and expectation of students $(51 \%$ of the students are not satisfied with their major education and $43.3 \%$ do not recognize the professionalism); it is also the important influencing factor that students' cognition of education and industry do not reach the expectation level of education (56.3\% of the students are not willing to be engaged in related industries; $51 \%$ think the tourism major does not a bright future).

At present, the third batch colleges in our country do not attach enough importance to students' major cognition; students do not have many ways of gaining knowledge of their related major and do not have mature ability of information search and judgment, which will have direct impact while knowing the tourism major and choosing the employment industry. Through professional learning, students will gradually know more about the tourism major; however, their school education and preliminary cognition still has a large gap with the social industries, leading to the gap between students' expectation of the industry and the actual perception and the fact that the professional knowledge they learn in the school cannot meet the demands of their work. Therefore students do not have a correct understanding of their major and even refuse to do related work.

(2) In terms of cultivation target, most students do not have a clear understanding of the cultivation target of tourism major in the third batch colleges $(56.3 \%$ of the students do not know the cultivation target; $45 \%$ hold that the cultivation target lacks characteristics) and think that the cultivation target of the school does not provide much help for them $57.7 \%$ think that the major does not help employment at all; $43 \%$ think that what they have learned does not enrich their self-ability). At present, the cultivation target is mainly formulated according to their own conditions and characteristics of the major; however, third batch colleges do not combine with the current situation of the industry and the demands of students. The cultivation target directly influences the curricula provision, the knowledge structure and ability cultivation of students, leading to the fact that the cultivation targets of tourism major are similar and the knowledge and ability structure of the talents is imbalanced.

$56.5 \%$ of the students expect that besides professional knowledge and skills, they can also gain learning ability, service awareness and 
ability and techniques of interpersonal communication. Therefore, in formulating the cultivation target, tourism major of third batch colleges should not only combine with the conditions and characteristics of the schools, but also focus on the demands of the industry and student's expectation so as to formulate the more detailed cultivation target with characteristics of the colleges.

(3) In terms of curriculum provision, $48.2 \%$ of the students think that the curriculum provision is not reasonable; only $16.4 \%$ of the students think that the curricula are useful. For the existing problems in curriculum provision, 'insufficiency of practice curriculum' is highlighted (the choice rate is $49.3 \%$ ); practice curriculum can best combine the class theory with the social practice. And the practice curriculum in the colleges is set mainly according to the current conditions of the schools; students mainly study in the schools. Combination of schools and enterprises still has much difficulty. How to combine the practice curriculum with the current situation of the industry and the enterprises is what the third batch colleges should full think of.

Chart 3: existing problems in curriculum provision

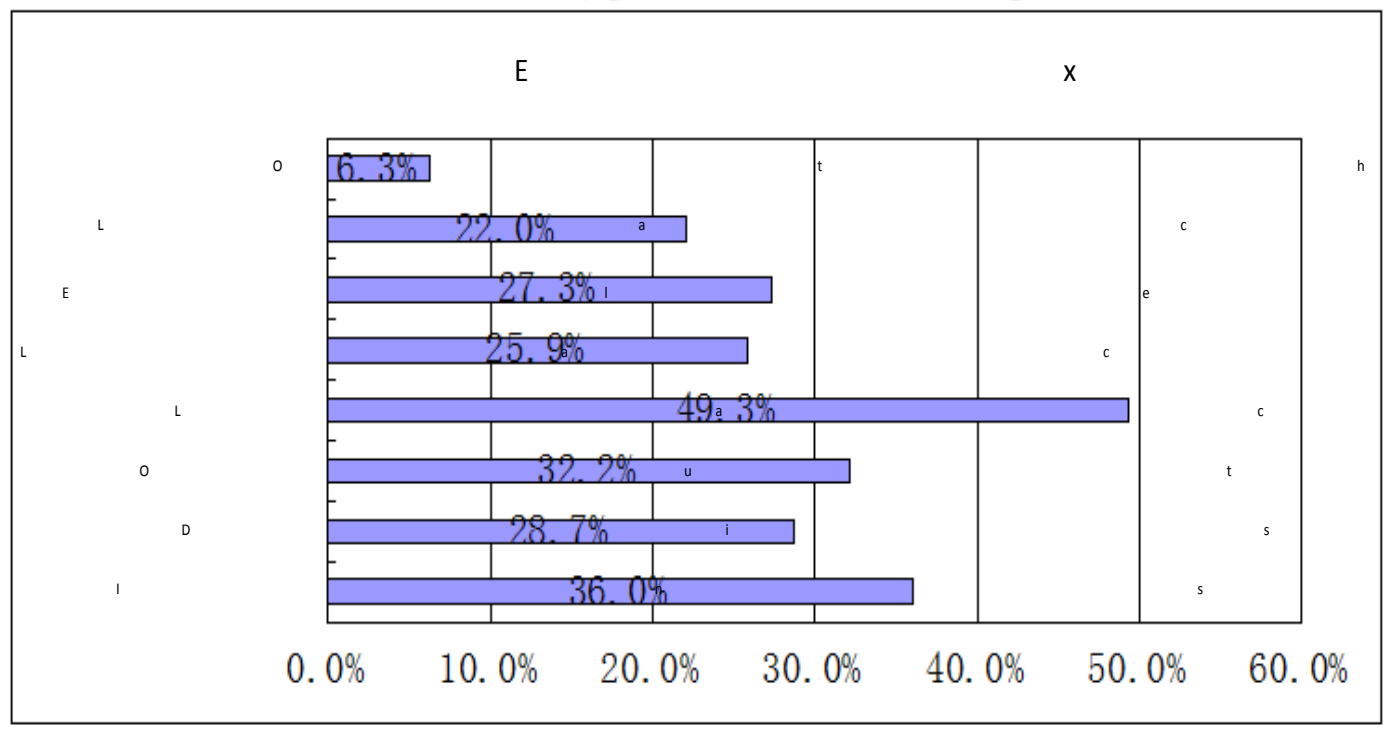

In terms of student's requirements of major internship, $50.7 \%$ of the students expect to strengthen pre-internship training, which shows the difference between the major education and the skills required by the actual enterprise operation. Meanwhile, employment guidance of students in school is very important to the communication between students and enterprises in the internship process. 
Chart 4 Major internship demands of students

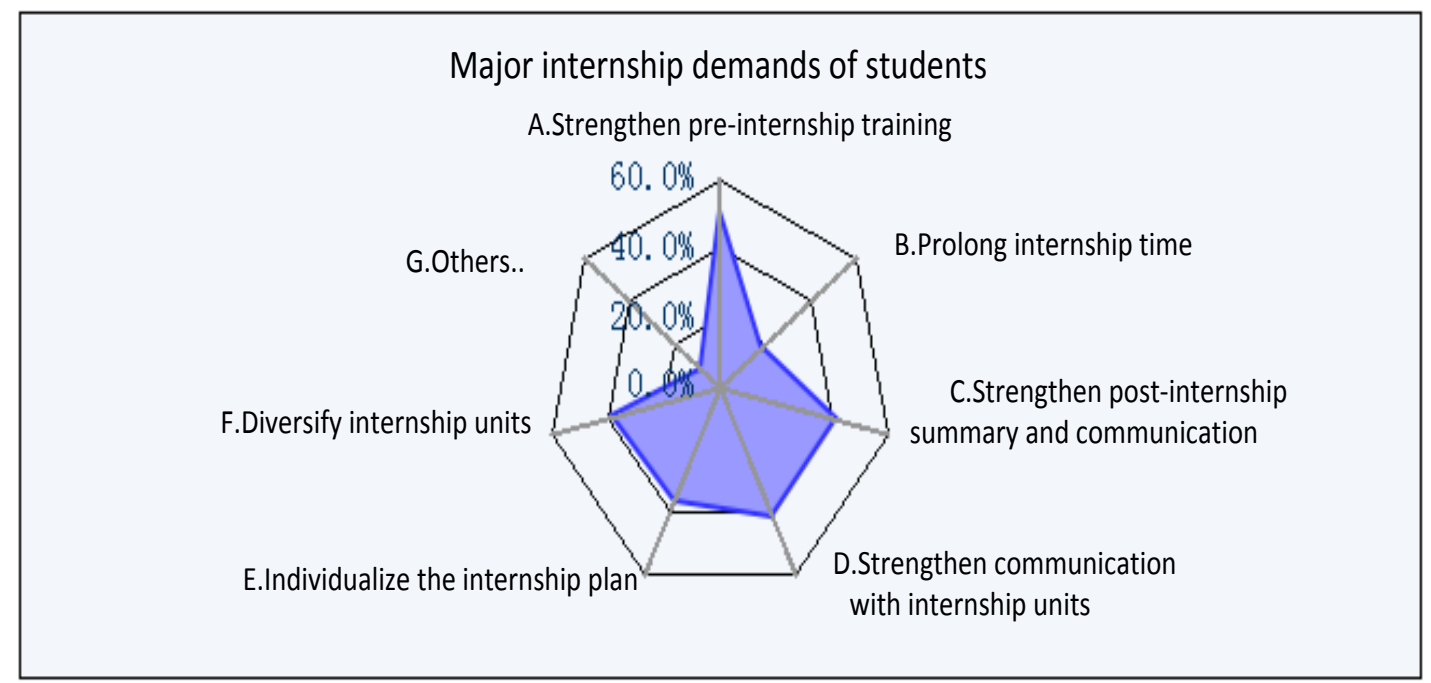

(4) In terms of teaching form, only $18.2 \%$ agrees with the lecture-oriented teaching mode; $47.6 \%$ are not satisfied with it; $44.4 \%$ do not have high activeness and participation in class. $55.6 \%$ hope that the schools can diversify the teaching methods and forms and comprehensively cultivate the multiple qualities of tourism major rather than simply teach the basic theory through textbooks. And tourism major has strong practicability and requires the multiple abilities of students; it has strong demands for the practical class education. In the teaching process, multiple methods such as picture, video and multi-media courseware should be adopted so as to vividly narrate the professional knowledge.

(5) In terms of teaching team, at present, the high-level talents with master's degree and doctor's degree are not enough, which cannot satisfy the demands of colleges for tourism teachers, hence students are not that satisfied with the teaching team of third batch colleges. $63.6 \%$ of the students are not satisfied with teaching of teachers; over $65.4 \%$ think that the teachers' teaching is of no value. It shows that deviation exists between education of tourism major and students' demands, in which professionalism of teachers and teaching methods will directly influence students' knowledge-receiving ability and their cognition of the major.

Students attach great importance to the professionalism, practice experience and teaching ability of professional teachers, showing that students desire to combine the college education with the industrial education; they also hope that the professional teachers have the unique and attractive teaching ability. Colleges should pay attention to cultivating and introducing in professional talents, have regular practice training of professional teachers or conduct the training by the enterprises and schools so as to strengthen the practice experience of professional teachers. 
Chart 5 Abilities Professional Teachers should Possess

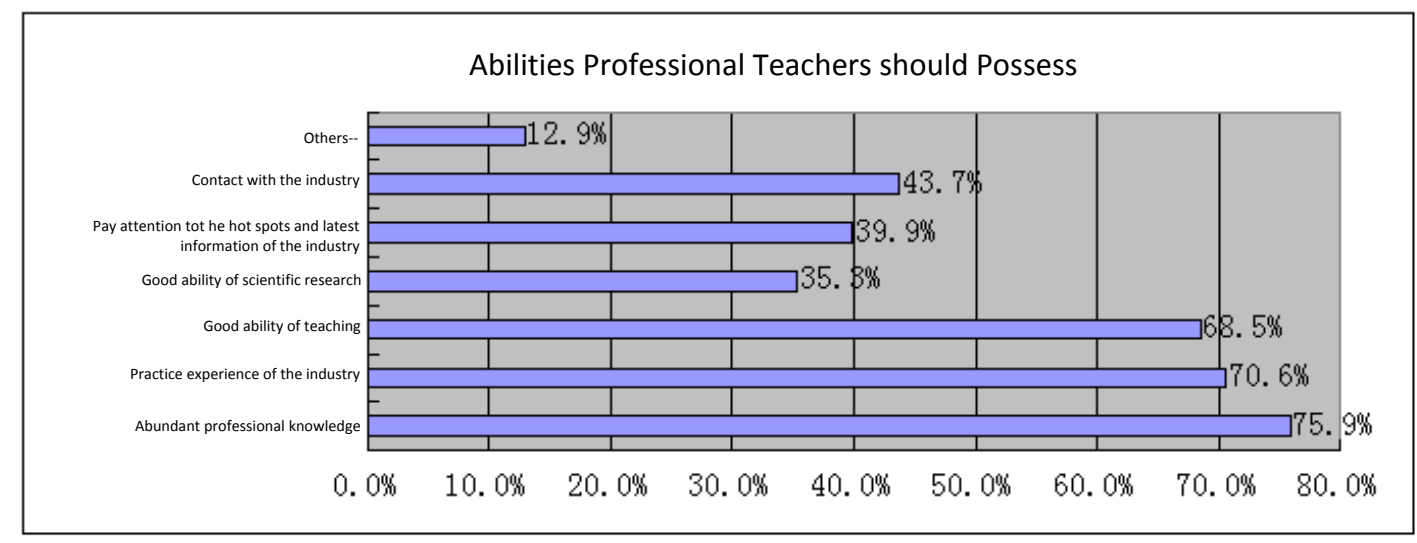

\section{Suggestions for 'Employment-oriented' Talent Cultivation Mode of Tourism Major in Third Batch Colleges}

The ultimate goal of education is to enable talents to gain enough cultural knowledge, life and production skills and then enter into different industries in the society to devote themselves to the society. Cultivation of tourism majors' competitiveness of their own industry and other industries in third batch colleges is obvious insufficient; the employment function has been weakened. Hence, 'employment-oriented' talent cultivation mode is the talent cultivation plan formulated by the school according to the market demands so as to ensure the cultivation mode of application and technique abilities. Through combining the above investigated talent cultivation mode of tourism majors and the employment demand deviation of students, the paper proposes some suggestions for optimization of talent education mode of tourism majors in third batch colleges from the perspectives of cultivation target, curriculum provision, teaching form, teaching staff and employment guidance.

(1) Concretizing Cultivation Target

In the 'employment-oriented' talent cultivation mode, the target and specifications of talent cultivation should give full considerations to the employment and future career of students; the 'knowledge-oriented' talent cultivation mode has not adapted the talent demands of constantly changing tourism market. Therefore, third batch colleges should observe the trend and situation of the industry at any time and keep adjusting so as to adapt to the development tendency of tourism industry and the change of talent demands; they should also conduct scientific investigation and analysis of tourism market and improve the cultivation target according to the different requirements of talents proposed by the tourism market in the different phases.

(2) Applying Curriculum Provision

On the basis of adequate market investigation, tourism major in third batch colleges should embody the applicability of curriculum provision. The nature of 'employment-oriented' talent cultivation is to cultivate the talents suitable for the market. Before curriculum provision, make full investigations as to what kind of talents the society needs; then set the curricula through combining the conditions of the school. Whether the curriculum provision is reasonable influences the development of the school to some extent. Meanwhile, curriculum provision directly influences the specification and quality of talent cultivation. Curricula should be set according to the cultivation target, educational and teaching discipline and the physical and psychological development rules of students. Curriculum provision should focus on the employment ability of students; knowledge, skills and attitudes that the posts require should be embodied in the curricula and realized 
through curricula.

(3) Diversifying Teaching Form

First of all, professionalize the class teaching form. The class teaching of tourism majors in third batch colleges should fully embody the uniqueness of tourism major and do not simply stimulate other majors. Staffs of all levels engaged in teaching work of tourism major should actively study and discuss the differences between this major and other majors and fully tap the specialties of majors so as to ensure that the teaching contents of tourism major reflect the market demands of the industry; The orientations of tourism major should be independent; whether they cultivate the tourism management talents or hotel management talents should be obviously distinguished in their own orientation lessons so as to have their own styles and avoid mutual disturbance.

Second, highlight the practice teaching form. 'Employment-oriented' talent cultivation is to cultivate talents for the market; the enterprises, as the main body of the market, should also participate in talent cultivation and provide conditions for talent cultivation. Hence, both the schools and enterprises should make full use of the current favorable conditions, fully integrate the education resources and maximize the resource share. In the process of student cultivation, enterprises participate in talent management, apply the advanced management methods and ideas of the enterprises to the talent cultivation mode and organically connect the enterprise management to the school management, which is good for students to improve their adaptability to the social environment. The schools should make full use of the arena and equipment of the enterprises and cultivate the practice ability of students.

(4) Strengthening Teaching Team

Many teachers in the tourism major of third batch colleges were primarily transferred from non-tourism to tourism major through short-term learning. Such teachers own abundant theoretical and teaching experience, who are capable of teaching lessons but cannot reach the required levels of the professional teachers in terms of the entire mastery of tourism knowledge and professional manipulation skills. The insufficiency of teachers' ability directly leads to the problems of professional learning and future employment of tourism majors. Hence the schools should provide the convenient conditions for professional teachers in terms of professionalized learning. Meanwhile, the third batch colleges should hold the seminars for the professional teachers to exchange their knowledge and teaching experience; teachers can learn from others' strong points and keep re-knowing their abilities, expanding the professional knowledge and improving the teaching methods and modes.

(5) Orienting Employment Guidance

The direct target of 'employment-oriented' talent cultivation is to help students find jobs. The good employment guidance is of great significance to both the graduates and the higher tourism educational colleges that cultivate talents. In our country, most of the employment guidance courses are elective; many students do not have profound understanding of 'employment', which indirectly prevents students from choosing the jobs according to their own characteristics. The work of tourism industry is easily misunderstood by the masses; hence, employment guidance provided by the higher tourism education for the students is of great importance. Therefore, after cultivation, schools should arrange the qualified graduates to work in the tourism enterprises and ensure them to find jobs. Therefore, 'employment-oriented' talent cultivation mode is set up on the basis of multiple cooperation, with clear employment orientation. Those enterprises participate in talent cultivation and provide conditions can greatly mobilize the activeness of the schools, students and enterprises, which is a high-level production-learning cooperative form. 


\section{Conclusion}

Based on the employment orientation of students, this paper conducts related investigations and research concerning the deviation of talent mode in tourism major in third batch colleges to the employment demands of students; through research of related literature and analysis of questionnaires, it does need improving. At present, the talent cultivation mode of tourism major in third batch colleges does not completely accord with the employment demands of the students. It is because that the higher tourism educational colleges still adopt the traditional educational thoughts and examination-oriented education is the main teaching form, which lack communication with tourism industries and the quality demands of professional students. Tourism industry needs the talents that accord with the enterprise demands; students in tourism management majors need the higher educational mode that meets their different demands.

Optimization of higher educational mode of tourism should start from the actual conditions of the schools and deeply tap the characteristics. Targeted at guaranteeing the talent demands of tourism enterprises, meeting the students' demands of the tourism management majors and ensuring the good employment ability of students, cultivate the tourism talents with the features of different educational layers and different types.

\section{Acknowledgements}

Funded project: provincial project subject of teaching reform research of higher institutions in Jiangxi in 2014 Research of 'Employment-oriented' Talent Cultivation Mode of Tourism Major in the Third Batch Colleges (Subject No.: JXJG-14-28-5)

\section{Reference}

[1] Ministry of Education of the People's Republic of China. Statistics Data. Website of Ministry of Education http://www.moe.gov.cn.2015.10

[2] Zhang Hansong. Construction Research of Innovative Experimental Zone of Talent Cultivation Mode of Tourism Major in Third Batch Colleges--Taking the Example of College of Science and Technology of Guizhou University. Tribune of Education Culture. 2011 (6):42

[3] Wang Xueting. Research of Mode Optimization of Tourism Higher Education in Our Country Based on Employment Orientation of Students. Collected Papers of Liaoning Normal School. 2014 (3): 30-31

[4] Zhang Huixia. Strategic Concept of Higher Tourism Education Reform. Journal of Shanxi University of Finance and Economics: Higher Education Version. 2006 (01): 19-21 